\title{
Expression of Concern
}

\section{Expression of Concern: Klingener et al., "N-Cadherin Promotes Recruitment and Migration of Neural Progenitor Cells from the SVZ Neural Stem Cell Niche into Demyelinated Lesions"}

JNeurosci is publishing an Expression of Concern for the article, "N-Cadherin Promotes Recruitment and Migration of Neural Progenitor Cells from the SVZ Neural Stem Cell Niche into Demyelinated Lesions," by Michael Klingener, Manideep Chavali, Jagdeep Singh, Nadia McMillan, Alexandra Coomes, Peter J. Dempsey, Emily I. Chen, and Adan Aguirre, which appeared on pages 9590-9606 of the July 16, 2014 issue. The editors have been made aware of questions about the reliability of the data presented in Figure 2, $C$ and $D$, and Figure 4, E and $F$. JNeurosci will make a final decision on this article pending a full investigation and reproduction of the results and conclusions presented in the article.

DOI: 10.1523/JNEUROSCI.0612-21.2021 